\title{
Direct peroral pancreatoscopy with an ultraslim endoscope for the evaluation of intraductal papil- lary mucinous neoplasms
}

It is often difficult to distinguish between benign and malignant intraductal papillary mucinous neoplasms (IPMNs) of the pancreas and to determine their exact extent. Peroral pancreatoscopy including narrow-band imaging (NBI) is useful for the evaluation of these neoplasms $[1,2]$, but it is technically difficult and requires two skilled endoscopists and endoscopic systems [3]. The ultraslim upper endoscope has been proposed for direct visual examination of the biliopancreatic duct by a single operator $[4,5]$. However, the usefulness of direct peroral pancreatoscopy (D-POP) is clinically limited by the inconsistent success rates owing to the inability to keep the position of endoscope stable. An intraductal balloon passed through the endoscope may permit ease of access and stable positioning of the endoscope within the pancreatic duct. After anchoring the intraductal balloon within the proximal pancreatic duct, the endoscope can be advanced over the balloon catheter.

The feasibility of intraductal balloon-guided D-POP with NBI was evaluated in four patients with IPMNs ( $\bullet$ Fig. 1). An ultraslim upper endoscope (GIF-XP260N; Olympus, Tokyo, Japan) was advanced directly through the major papilla into the pancreatic duct assisted by a 5 -Fr intraductal balloon catheter (MTW Endoskopie, Wesel, Germany) ( Fig. 2, Video 1 ). NBI and forceps biopsy were carried out during D-POP, which showed the papillary tumor with villous lesions in the pancreatic duct ( $\bullet$ Fig. 3). NBI showed the surface structure and capillary vessels of the lesion with greater clarity ( $\bullet$ Fig. 4 , Video 2 ). All patients successfully underwent intraductal balloon-guided D-POP with NBI without procedure-related complications. Biopsy specimens showed adenocarcinomas in two patients and adenoma with dysplasia in one patient ( Fig. 5), all of whom were recommended surgery. The fourth patient had chronic inflammation and is being followed up regularly.

In conclusion, the high success rate in this case series illustrates the feasibility of using intraductal balloon-guided D-POP with an ultraslim endoscope in patients with IPMNs.

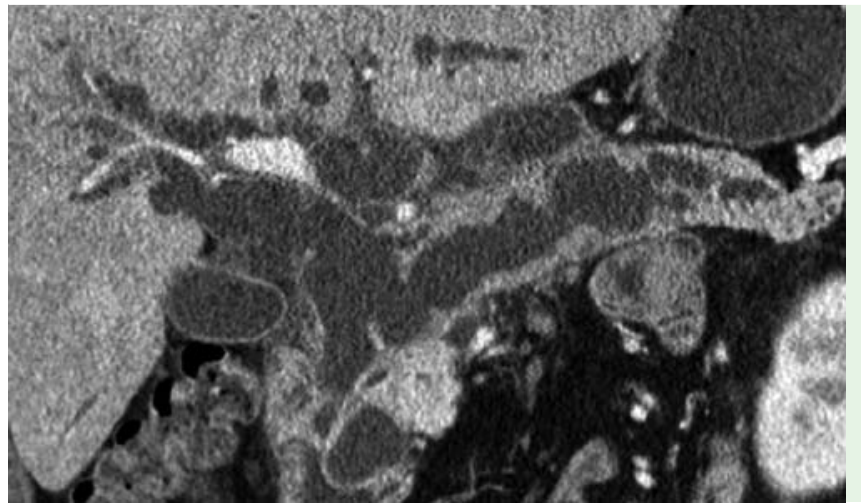

Fig. 1 Curved multiplanar reconstructed computed tomography image showing marked dilated main pancreatic duct and bile duct.

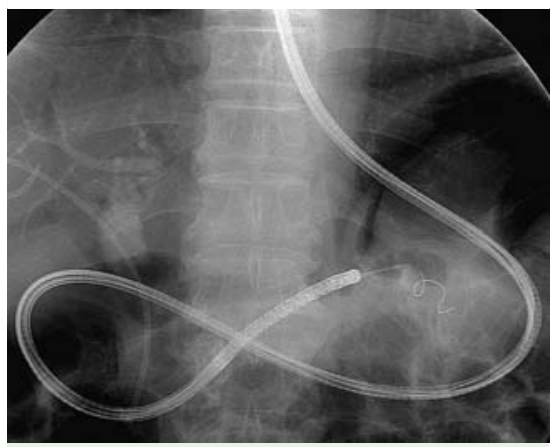

Fig. 2 An ultraslim upper endoscope inserted into the pancreatic duct assisted by an intraductal balloon catheter.

\section{Video 1}

Intraductal balloon-guided direct peroral pancreatoscopy (D-POP) using an ultraslim endoscope advanced from the distal to proximal pancreatic duct assisted by an intraductal balloon catheter.

\section{Video 2}

An ultraslim endoscope for direct peroral pancreatoscopy (D-POP) advanced into the pancreatic duct and providing images of a villous and papillary mass. Narrow band imaging (NBI) observation more clearly identified the lesion's surface structure and microvessels.

\section{Acknowledgment \\ $\nabla$}

The authors thank Olympus Korea for providing the ultraslim upper endoscope for this study.

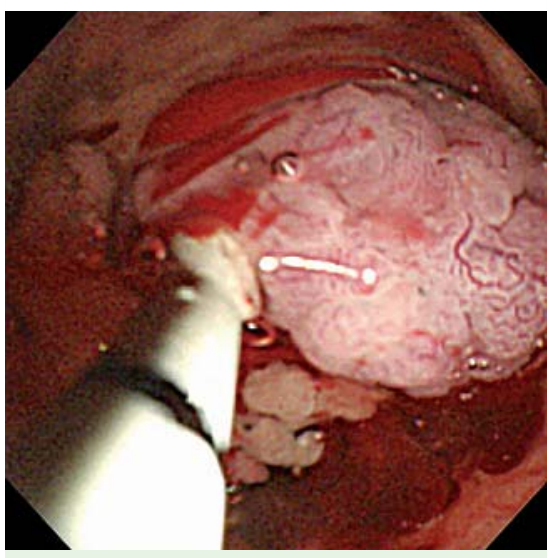

Fig. 3 Direct peroral pancreatoscopy with an ultraslim endoscope showed a papillary tumor with villous lesions.

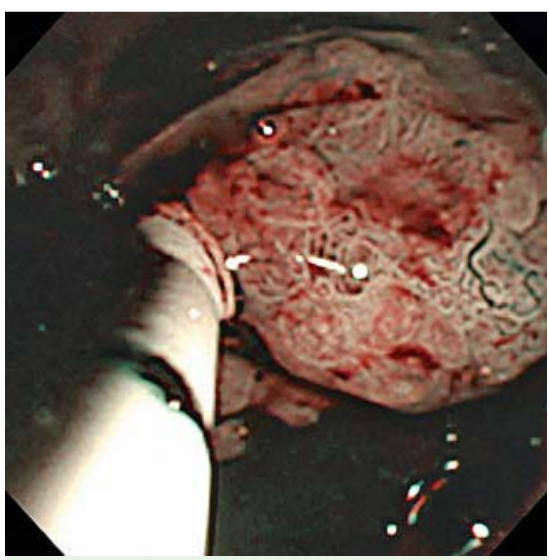

Fig. 4 Narrow band imaging (NBI) showed the surface structure and capillaries in the lesion with greater clarity. 


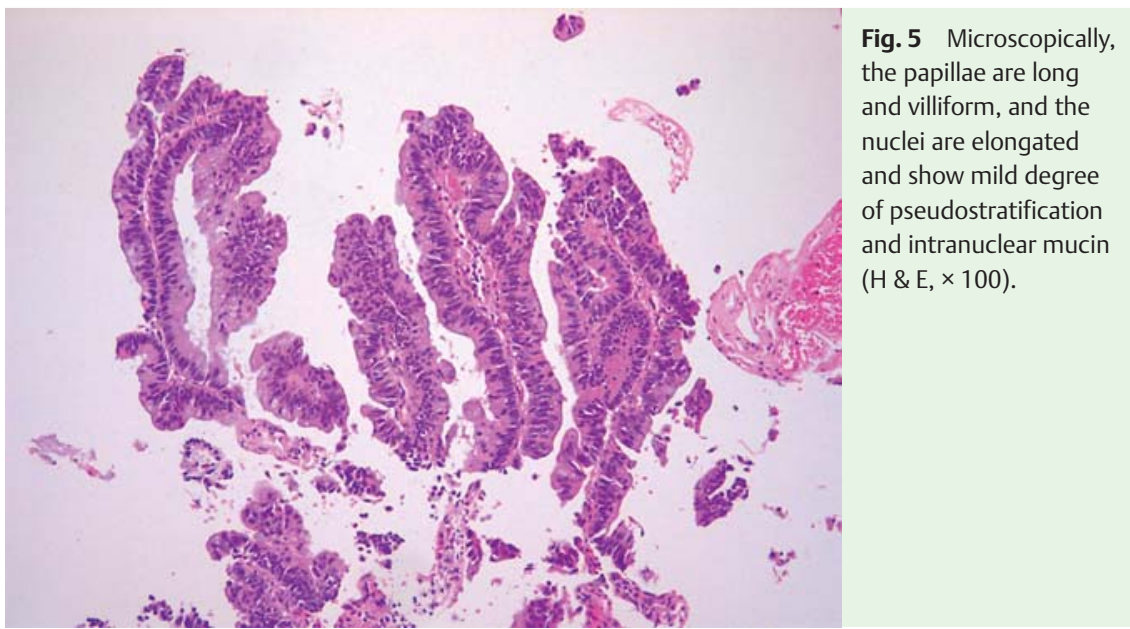

Endoscopy_UCTN_Code_TTT_1AR_2AB

\section{Competing interests: None}

Y. K. Cheon ${ }^{1,2}$, J. H. Moon ${ }^{1}$, H. J. Choi ${ }^{1}$, J. E. Lee ${ }^{1}$, Y. N. Lee ${ }^{1}$, Y. D. Cho ${ }^{1}$, T. H. Lee ${ }^{1}$, S. H. Park ${ }^{1}$, S. J. Kim ${ }^{1}$

1 Digestive Disease Center, Department of Internal Medicine, Soon Chun Hyang University School of Medicine, Bucheon and Seoul, Korea

2 Digestive Disease Center, Department of Internal Medicine, Konkuk University School of Medicine, Seoul, Korea

\section{References}

1 Hara T, Yamaguchi T, Ishihara Tet al. Diagnosis and patient management of intraductal papillary-mucinous tumor of the pancreas by using peroral pancreatoscopy and intraductal ultrasonography. Gastroenterology 2002; 122: 34-43

2 Itoi T, Sofuni A, Itokawa F et al. Initial experience of peroral pancreatoscopy combined with narrow-band imaging in the diagnosis of intraductal papillary mucinous neoplasms of the pancreas (with videos). Gastrointest Endosc 2007; 66: 793 - 797

3 Kozarek R, Kodama T, Tatsumi Y. Direct cholangioscopy and pancreatoscopy. Gastrointest Endosc Clin N Am 2003; 13: 593-607
4 Moon JH, Ko BM, Choi HJ et al. Intraductal balloon-guided peroral cholangioscopy with an ultraslim upper endoscope (with video). Gastrointest Endosc 2009; 70: 297 302

5 Krishna SG, McElreath DP, Rego RF. Direct pancreatoscopy with an ultrathin forwardviewing endoscope in intraductal papillary mucinous neoplasm of the pancreas. Clin Gastroenterol Hepatol 2009; 7: e75 - 76

Bibliography

DOI $10.1055 / \mathrm{s}-0030-1256933$

Endoscopy 2011; 43: E390 - E391

(c) Georg Thieme Verlag KG Stuttgart · New York . ISSN 0013-726X

\section{Corresponding author}

\section{J. H. Moon, MD, PhD}

Soon Chun Hyang University School of Medicine Digestive Disease Center

Soon Chun Hyang University Bucheon Hospital

1174 Jung-Dong

Wonmi-Ku

Bucheon 420-767

Korea

Fax: +82-32-6215080

jhmoon@schmc.ac.kr 